\title{
Let's sing, not shop: an economist dreams of a sustainable city
}

\author{
David Fell
}

When imagining a London of 2062, it is easy to get excited about the possibility of personalised jet packs, hover cars and low-cost space travel. My personal hopes are just as fantastical: I want to see microwave oven-sized waste disposal machines, which generate energy and heat as a by-product, in every home; and 3-D printers that use nano-materials to build the products I want at the touch of a button.

As these imaginings immediately illustrate, there are dangers in looking far ahead: we may simply be left looking absurd, either now or in the future, once it arrives.

Nevertheless, there are uses for long-range scenario-planning. Firstly, it can help us to make normative judgments - do we prefer this possible future or that one? And, secondly, by navigating back from our preferred future, we can begin to think about the kinds of things that we might do now, or soon, that would steer us in the direction of our preferences.

The idea that we can choose our direction of travel is not merely an expression of belief in the power of democracy. It is also an assertion about the nature of an economy. An economy is not a closed system that tends towards dynamic equilibrium, the parameters of which are deterministic: it is, rather, a complex, adaptive system, the rules of which are socially determined and contingent. The economy is a human construct and, as such, we have the ability - and, indeed, the responsibility - to shape it to suit our needs. Over a period as long as fifty years, we should certainly be able to make the kinds of choices that will steer our economy in one direction rather than another.

The 'steering' is not, however, some mechanical act, in which we pull various levers and pulleys to make the 'machine' go in the direction we want. It is, rather, a more subtle and ultimately powerful process in which underlying behavioural norms are challenged and modified in a far more organic fashion.

I want to suggest that there is available to us a much more sustainable London in 2062, and a much less sustainable one; and which one we end up with will be, in large part, a function of the way in which a variety of norms pan out and interact. Here are three examples:

Masculine/feminine - London is presently a macho city, characterised by needlessly tall buildings, aggressive corporate behaviour, narcissistic decision-making and damagingly ruthless individualism. Left unchecked, these behaviours will continue to generate extreme levels of social inequality, the unrestrained

How to cite this book chapter:

Fell, D. 2013. Let's sing, not shop: an economist dreams of a sustainable city. In: Bell, S and Paskins, J. (eds.) Imagining the Future City: London 2062. Pp. 119-121. London: Ubiquity Press. DOI: http://dx.doi. org/10.5334/bag.p 
consumption of finite physical resources and an environment of profound psychological stress for the majority of London's citizens. A more feminised city - attending to notions of care, concern, inclusion, small-scale production and consumption - would, by contrast, inherently counter such trends. A more sustainable London in 2062 would come about not through direct measures to, say, reduce $\mathrm{CO}_{2}$ emissions, but instead, indirectly and more powerfully, through the development of a greater ethic of care.

Walled/open - a great deal of London's economic life currently happens behind walls. Corporate decision-making is opaque: wealthy citizens immunise themselves from their 'neighbours' by living in gated communities; political processes are dominated by lobbyists and careerists conversing in inaccessible settings. A London of 2062 in which these barriers persist would probably function as a city, but it could not possibly be described as sustainable. A sustainable London would be one in which inclusion and participation was ordinary, in which openness and transparency were normal. In this more open London, social injustices, environmental harms and wealth inequalities would be more apparent to all, increasing both the demand for change, and the political will to act. Improved outcomes would emerge organically from the change in the underlying logic of social interaction and would not need to be 'engineered' through interventions from 'the top'.

Material/de-material - the London of 2012 remains a citadel to consumer-led capitalism, even in the teeth of recession. Londoners, and the tens of thousands of tourists that visit the city, go shopping as if the world is going to end (!) and spend stupendous amounts of money on largely pointless products. It is conceivable that this could continue and that a London of 2062 will be wealthy enough to protect itself from the reality that will by then have come about, in which the effects of climate change will have become severe and in which a great many natural resources are either seriously depleted or have already vanished. But better, surely, to begin the process of weaning ourselves off our addictions, and to de-materialise our economy and our lifestyles. Let's learn rather than spend; let's sing rather than shop; let's stop with all the stuff.

At a time when unemployment in London - and, indeed, the rest of the UK and across Europe - is so high, and when governments and politicians are frantically seeking the economic growth that will save us from the present debt crisis, there is a risk of appearing somewhat disingenuous when offering suggestions for the short term that do not appear immediately to address the urgent problems faced by so many fellow citizens.

But it is at precisely such a time that the 'new' is required. It would surely be a mistake of the worst kind to spend inordinate efforts to return to some mythologised 'business as usual, for the sake of short term credit, when it is so obvious - to everyone? - that it was 'business as usual' that got us into this mess. In such a spirit, and in light of the three longer term themes just discussed, I offer three propositions for immediate action that could, I believe, not only begin steering London in the direction of genuine sustainability but could also deliver some shorter term gains that would benefit us all.

Firstly, I would like to see the language of competition replaced by the language of collaboration. Individuals and communities naturally collaborate with one another, but the discourse of business and politics has become monopolised by notions of endless competition. We need to reclaim the discourse, and reshape the space within which we make our decisions.

Secondly, I'd like to see a dramatic increase in the extent to which social and economic assets are under the direct ownership and control of communities. This would help to de-couple the 'real' economy from the financial economy; and would give individuals and communities a much more direct stake in the future.

Thirdly, I'd like to see us attend to the notion of 'sustainable play'. Human beings are inherently creative, sociable animals, but this better side of our nature has, like so many other aspects of our lives, been appropriated by market capitalism. We need to claim it back and demonstrate (to ourselves, as much as anything) that we can interact, exchange and be fulfilled without reliance on a piece of branded equipment. We don't see many advertisements encouraging us to go for a walk, for example, for the simple reason that it is exceptionally difficult for a corporation to make money out of us if we're out and about doing nothing so complicated as having a stroll. But going for a walk could, from such a perspective, be the most radical thing you do all day. Go ahead: take that step. 


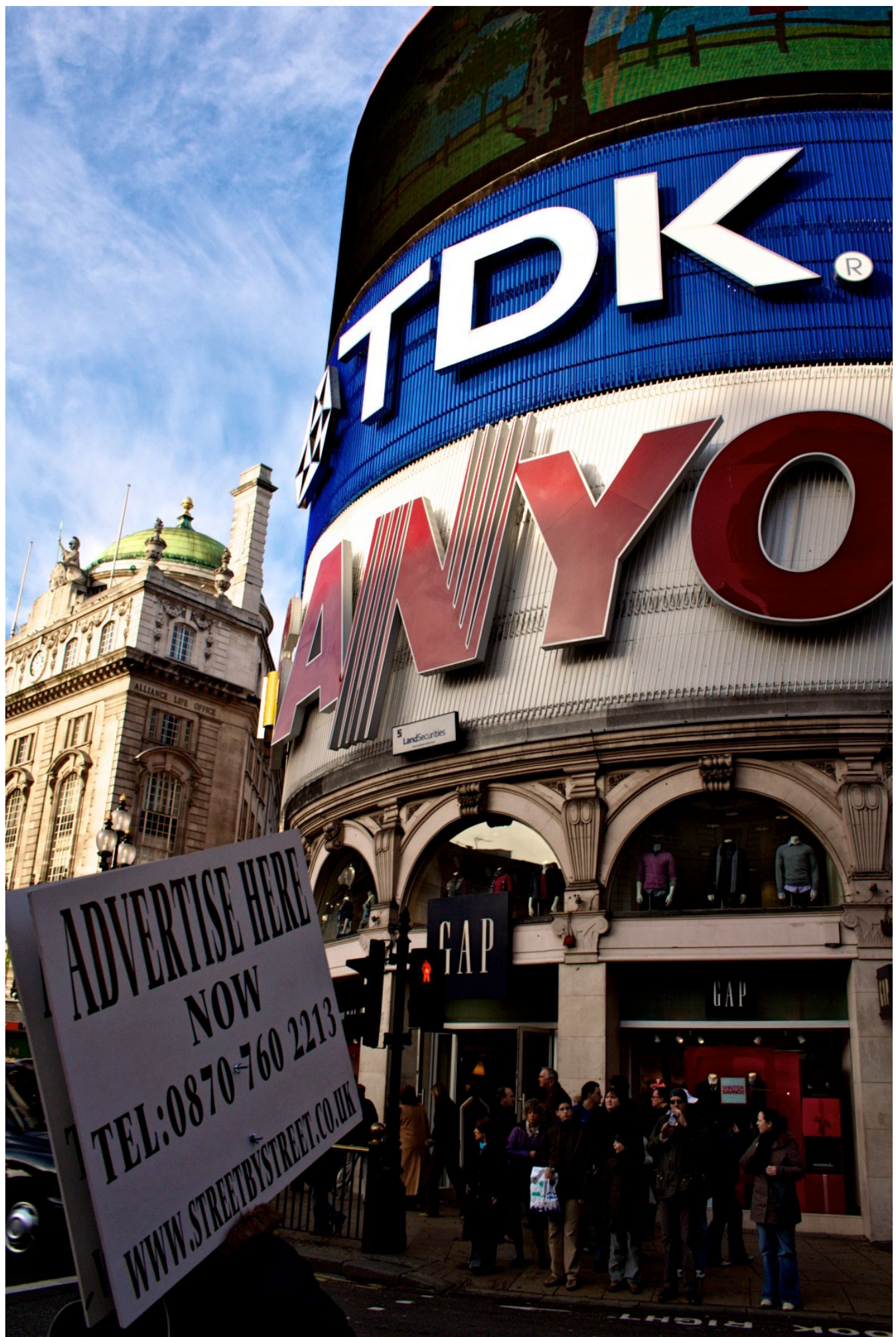

